\title{
The reference values of peak expiratory flow rate in Thailand children
}

\author{
Klaita Srisingh, Chutima Phuaksaman
}

Department of Pediatrics, Faculty of Medicine, Naresuan University, Phitsanulok, Thailand

Contributions: (I) Conception and design: K Srisingh; (II) Administrative support: C Phuaksaman; (III) Provision of study materials or patients: C Phuaksaman; (IV) Collection and assembly of data: K Srisingh; (V) Data analysis and interpretation: C Phuaksaman; (VI) Manuscript writing: All authors; (VII) Final approval of manuscript: All authors.

Correspondence to: Chutima Phuaksaman. 99 Moo 9 Phitsanulok-Nakhon Sawan Road, Tha Pho Subdistrict, Department of Pediatrics, Faculty of Medicine, Naresuan University, Phitsanulok 65000, Thailand. Email: chutimaph@nu.ac.th.

Background: Daily evaluation of peak expiratory flow rate (PEFR) is quite useful for monitoring and adjusting an asthmatic patient's treatment. Many factors including geography, ethnicity, socio-economic conditions, gender, and anthropometric play a role in lung function differences studies have found. The aim of this study is to present normal PEFR and to establish a PEFR equation for Thai children living in a suburban environment.

Methods: This study includes a cross-section of healthy children aged 6 to 18. It was conducted in Phitsanulok Province in the lower north of Thailand. The children were chosen to participate from five primary and secondary schools over the period from February 2014 to January 2015. The children were instructed on how to use the Wright peak flow meter (Clement Clarke International Ltd.). All of the participants performed PEFR 3 times and the highest value was recorded.

Results: A total of 2,000 students were initially examined; 80 students were excluded from the study. A total of 1,920 healthy children were recruited between the ages of 6 and18 years. Among them, 719 (37.4\%) were males and 1,201 (62.6\%) were females. The median age was 18 [12-18] years old, mean height, weight, body mass index (BMI) and PEFR were $155.98 \pm 14.99 \mathrm{~cm}, 51.38 \pm 16.95 \mathrm{~kg}, 20.62 \pm 4.79 \mathrm{~kg} / \mathrm{m}^{2}$ and $339.31 \pm 113.55 \mathrm{~L} / \mathrm{min}$, respectively. PEFR has a linear relationship in regards age, weight, height and BMI. For males, age was the strongest factor associated with PEFR ( $\mathrm{r}=0.838, \mathrm{P}<0.001)$. Females had a highly significant correlation between height and PEFR $(\mathrm{r}=0.532, \mathrm{P}<0.001)$. The regression equations are $\mathrm{PEFR}=$ $(1.34 \times$ height $)+(1.41 \times$ weight $)+(16.56 \times$ age $)-137.88$ for males $\left(\mathrm{R}^{2}=0.751, \mathrm{P}<0.001\right)$ and $\mathrm{PEFR}=(1.31 \times$ height $)+(0.94 \times$ weight $)+(7.30 \times$ age $)-55.27$ for females $\left(\mathrm{R}^{2}=0.507, \mathrm{P}<0.001\right)$.

Conclusions: This research study has provided the normal range of PEFR for Thai children aged from 6 to 18 years in Phitsanulok. The data was obtained using the Wright peak flow meter. Height, weight, and age were the significant determiners of the PEFR for each sex in the regression equation.

Keywords: Peak expiratory flow rate (PEFR); children; asthma

Submitted Jul 10, 2020. Accepted for publication Oct 28, 2020.

doi: $10.21037 /$ jtd-20-1846

View this article at: http://dx.doi.org/10.21037/jtd-20-1846

\section{Introduction}

A pulmonary function test is an important tool in diagnosing respiratory diseases such as asthma, assessing disease severity, and to follow up with patients $(1,2)$. There are several tests available to evaluate the pulmonary function from a simple test such as spirometry and peak expiratory flow to the more complex and expensive tests such as wash-out of nitrogen, dilution of inert gases, and whole body plethysmography. Each test has its own indication (3). The peak expiratory flow rate (PEFR) is 
helpful for the monitoring of airway limitation as part of the Global Initiative for Asthma $(1,2)$. The use of PEFR is cheaper, simple to use and portable (4). Daily evaluation of PEFR is quite useful for monitoring and adjusting an asthmatic patient's treatment $(4,5)$. PEFR is the maximum flow rate generated during a forceful exhalation, dependent on the strength of the thoracoabdominal muscle. The process is done by having the patient inhale to the optimum lung capacity and exhale to the maximum expiration $(4,5)$.

Many factors including environment, ethnicity, socioeconomic conditions, gender, and anthropometric features play a role in lung function differences, as reported by many studies (3,4,6-11). It can be difficult to perform the test due to lack of cooperation from the patient and be suboptimal, making it hard to interpret. So, adult PEFR values do not correspond accurately to the PEFR values accorded to children. Furthermore, when applying previous research to Thailand, it is evident that international studies cannot be used as an indicator to be used with confidence $(8,9,12-16)$. In Thailand only one study has been undertaken and that focused on children living in an urban zone (17). The aim of this study is to present normal PEFR and to establish a PEFR equation for Thai children living in a suburban environment.

\section{Methods}

This study includes an observational cross-section of healthy children aged 6 to 18 years. It was conducted in Phitsanulok Province in the lower north of Thailand. The children were chosen to participate from five primary and secondary schools over the period from February 2014 to January 2015. Students were randomly selected representing each grade. Each subject was interviewed and given a complete check-up of the following: weight, height, body temperature, dysmorphic features, breath sounds, heart sounds, organomegaly and neurological signs. A student would be excluded for the following reasons: (I) recent disease of the respiratory tract during the previous 4 weeks or with a history of chronic respiratory disease including improved symptoms of asthma such as asthma, chronic lung disease. (II) A systemic disease influencing the respiratory tract including neuromuscular disease, skeletal deformity or any systemic disease that can have lung involvement such as autoimmune disease. (III) The existence of any underlying heart disease. (IV) The use of inhaled corticosteroids, bronchodilators or medication that involves the pulmonary tract function. (V) A history of cardiopulmonary surgery.
(VI) A history of tobacco smoking or substance abuse.

Each subject was required to have written consent provided by his or her parent or legal guardian, assent form in age 7-12 years and consent form for $>12$ years prior to participating in the study. The study was approved by Naresuan University Institutional Review Board (No. 155/57) and conducted in accordance with the Declaration of Helsinki (as revised in 2013). A minimal sample size for estimating population mean was 466 subjects. The healthy subjects included in this study were classified using demographic data which included the following criteria: age, sex, underlying disease, and height and weight. Each subject wore their school uniform and no shoes for recording the weight. Create a calm environment and adjust the room thermostat around $25-27{ }^{\circ} \mathrm{C}$ and have subject sit in an isolated chair for 10 minutes. The experienced technician was brought in to perform this task and guided the students during the measurement process of the PEFR. To eliminate bias, the same technician performed the procedure to all subjects and measure PEFR at the same time from 10.00-13.00. The children were instructed on how to use the Wright peak flow meter (Clement Clarke International Ltd.) to inhale deeply, and then exhale forcefully as fast and hard as they can through the mouthpiece. Each child blew three times at maximum effort both at the rest and standing positions. This was done without the use of a nose clip. The experienced technician corrected and reassessed the technique that includes good coordination and maximum muscular effort in the test. All of the participants performed PEFR 3 times and the highest value was recorded.

\section{Analysis}

The data was analyzed using SPSS 22.0. Continuous variables such as age, weight, height, BMI, and peak flow were reported as mean \pm standard deviation in normal distribution and median (IQR) in abnormal distribution and categorical variables such as sex. Pearson correlation coefficients were calculated to examine relationships between the independent variables (age, weight, height) and peak flow. Multiple linear regression analysis was used. A P value of $<0.05$ was regarded as significant.

\section{Results}

A total of 2,000 students were initially examined; 50 students were excluded from the study because of respiratory symptoms on the day of the testing and 23 


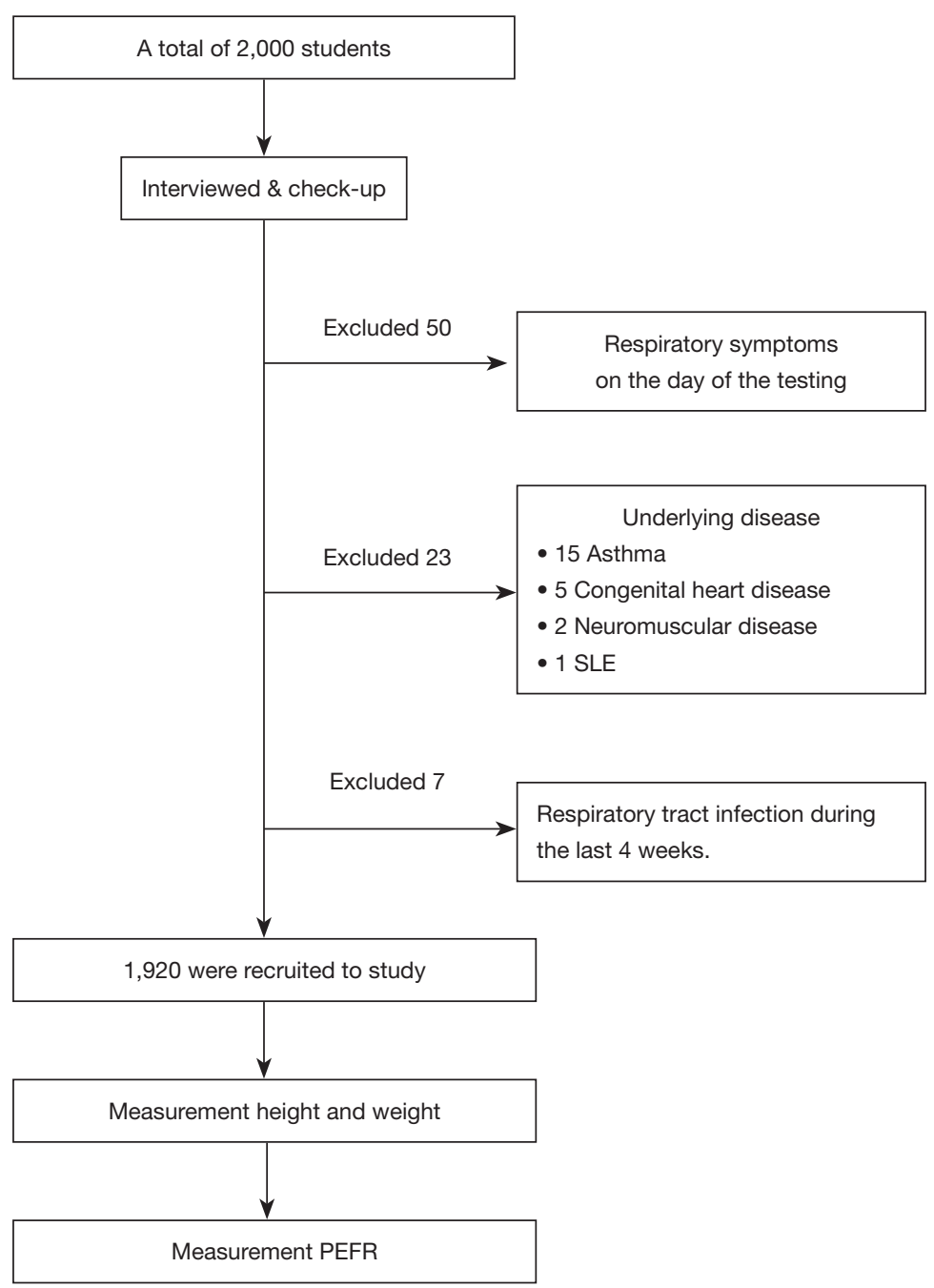

Figure 1 Flow chart of the enrollment process. PEFR, peak expiratory flow rate.

students were excluded due to underlying disease (15 asthma, 5 congenital heart disease, 2 neuromuscular disease, and 1 SLE) and 7 students because of recent disease of the respiratory tract during the last 4 weeks (Figure 1). A total of 1,920 healthy children were recruited between the ages of 6 and 18 years. Among them, 719 $(37.4 \%)$ were males and 1,201 (62.6\%) were females with the median age (IQR) of 18 [12-18] years, the mean height, weight, body mass index (BMI) and PEFR were $155.98 \pm 14.99 \mathrm{~cm}, 51.38 \pm 16.95 \mathrm{~kg}, 20.62 \pm 4.79 \mathrm{~kg} / \mathrm{m}^{2}$ and $339.31 \pm 113.55 \mathrm{~L} / \mathrm{min}$, respectively. Details of the data as separated by age are shown in Table 1 .

The scatterplots of PEFR have a linear relationship in regards age, weight, height and BMI (Figures 2-5). The graphs show an increase in lung function with increasing age, height, and weight. Males had a stronger correlation with PEFR than females. For males, age was the strongest factor associated with PEFR $(r=0.838, \mathrm{P}<0.001)$. Females had a highly significant correlation between height and PEFR $(r=0.532, \mathrm{P}<0.001)$. The BMI was the lowest correlation in this study $(\mathrm{r}=0.350, \mathrm{P}<0.001)$. We excluded the BMI in our equations for PEFR.

The regression equations are as follows:

* For males: PEFR $=(1.34 \times$ height $)+(1.41 \times$ weight $)$ $+(16.56 \times$ age $)-137.88$, R-squared $(\mathrm{R} 2)=0.751$, $\mathrm{P}<0.001$.

* For females: PEFR $=(1.31 \times$ height $)+(0.94 \times$ weight $)+(7.30 \times$ age $)-55.27, \mathrm{R}$-squared $(\mathrm{R} 2)$ $=0.507, \mathrm{P}<0.001$.

Integration of age, height and weight for regression 
Table 1 Mean height, weight and peak expiratory flow rate (PEFR) separated from age and sex

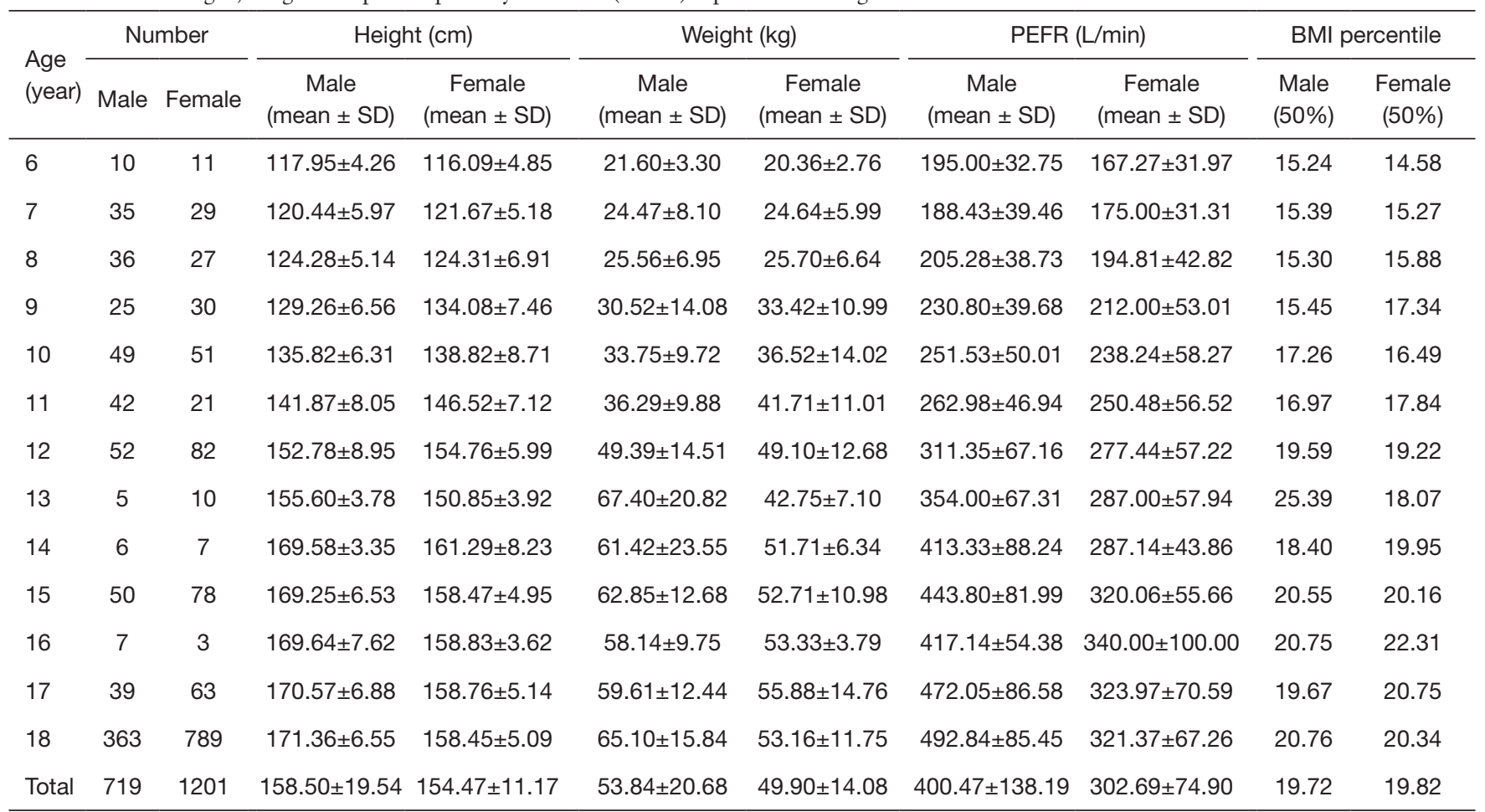

Data shows mean \pm standard deviation (SD). BMI, body mass index.

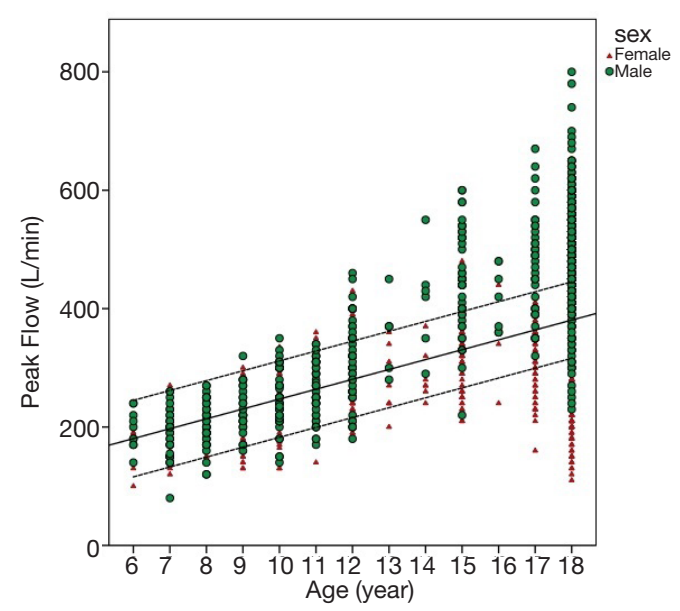

$r=0.540(95 \% \mathrm{Cl}: 0.512-0.566)$

Male: $r=0.838(95 \% \mathrm{Cl}: 0.815-0.859)$

Female: $r=0.507$ (95\% Cl: 0.456-0.551)

$(\mathrm{P}<0.001)$

Figure 2 Linear regression analysis of peak expiratory flow rate and age.

equation reported a significant coefficient than individual factor.

\section{Discussion}

Measurement of PEFR is an important tool for the evaluation of asthma control and has been used commonly worldwide (1-4) because it is a simple, noninvasive, quick, and inexpensive test. Several previous reports suggest a good correlation between PEFR and $\mathrm{FEV}_{1}$ and indicates that measuring the PEFR can be a reliable and useful tool for evaluating respiratory flow and management of asthma (3,18-21).

Our data indicates that the PEFR values have a higher 


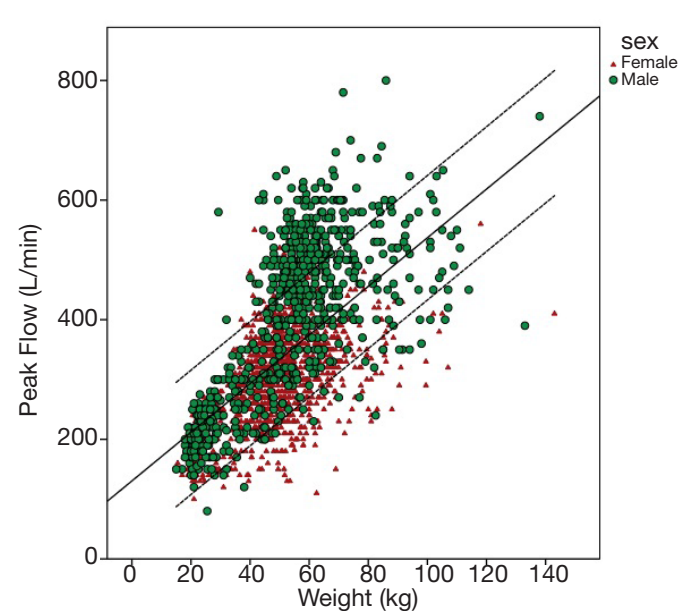

Figure 3 Linear regression analysis of peak expiratory flow rate and weight.

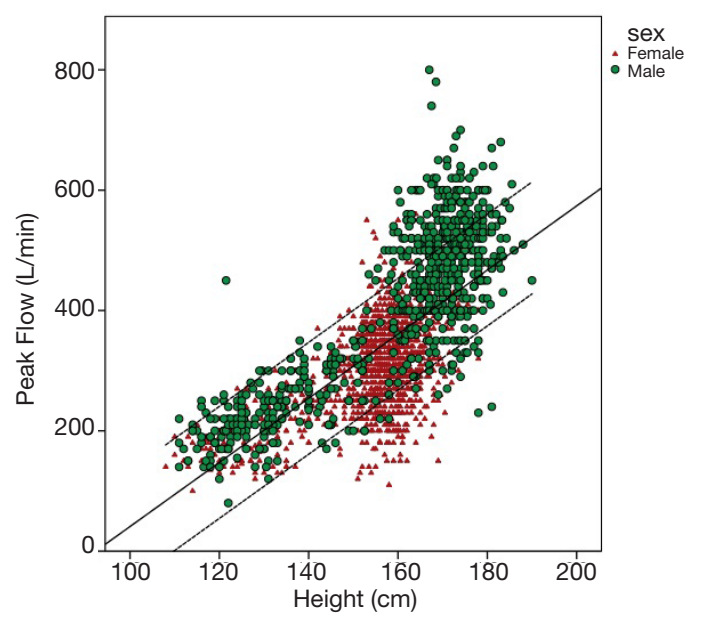

Figure 4 Linear regression analysis of peak expiratory flow rate and height. $\mathrm{r}=0.607$ (95\% Cl: $0.577-0.635)$

Male: $r=0.703$ (95\% Cl: $0.660-0.740)$

Female: $r=0.498(95 \% \mathrm{Cl}: 0.452-0.542)$

$(\mathrm{P}<0.001)$ $\mathrm{r}=0.703(95 \% \mathrm{Cl}: 0.682-0.724)$

Male: $r=0.819$ (95\% Cl: $0.795-0.842)$

Female: $r=0.532$ (95\% Cl: $0.488-0.570)$

$(P<0.001)$ significant correlation with males than females. Most of the other studies conducted have recorded similar trends $(7,22)$. This leads to a belief that differences in PEFR values between the genders occurs due to differences in airways and lung size, lung capacity, and the strength of respiratory muscles.

The height, age, and weight in this study correlate with the PEFR values found in other studies (5-7,15,23-31). Height is the highest correlation factor. $\mathrm{Cb}$ et al. (27) and many others studies $(23,24,31)$ have shown the same result. The PEFR trend also increased with age and height which may be due to growth development that increased muscularity and the size of the chest cavity during childhood and the adolescent period (28). Literature reviews $(23,24,30,31)$ have revealed a variation associated with weight for PEFR while in this current study significant correlation is shown. In this study, BMI has the lowest correlation factor with PEFR. The calculation of weight and height as BW $(\mathrm{kg}) /$ height $\left(\mathrm{m}^{2}\right)$, is not included in establishing the regression equation.

The regional difference also has an effect on PEFR. Pulickal et al. (26) found the normal value of PEFR in children in the south of India to be lower than those in the north of India. Carson et al. (32) study showed a significantly higher mean PEFR in rural children than children that live in urban areas. Benjaponpitak et al. (17) study, which was mainly conducted in Bangkok, the capital city of Thailand, showed correlation between PEFR with weight, height and age in males ( $r=0.79,0.85$ and 0.81 , respectively) and females $(r=0.73,0.81$ and 0.74 , respectively). However, their finding indicated the use of only height in regression equation, 


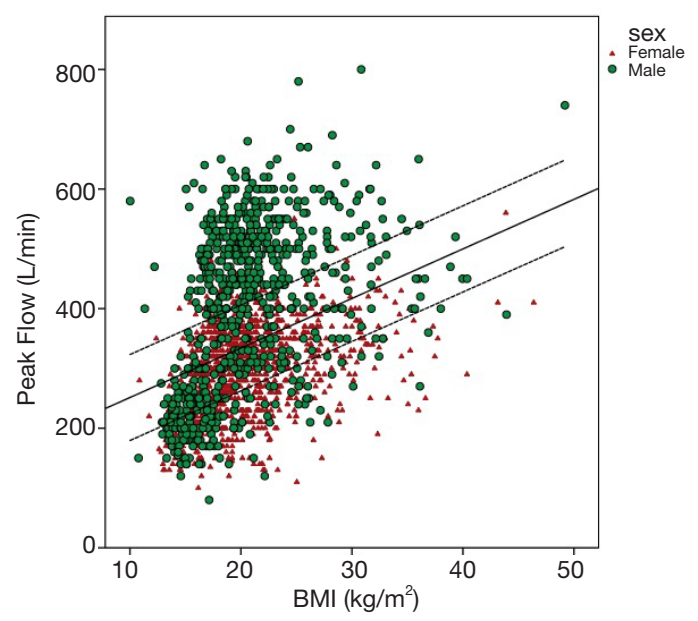

$r=0.350$ (95\% Cl: 0.308-0.390)

Male: $r=0.420(95 \% \mathrm{Cl}: 0.363-0.478)$

Female: $r=0.360(95 \% \mathrm{Cl}: 0.308-0.412)$

$(\mathrm{P}<0.001)$

Figure 5 Linear regression analysis of peak expiratory flow rate and BMI. BMI, body mass index.

Table 2 Comparison of regression equation in Thailand

\begin{tabular}{lll}
\hline Study & Male regression equation & Female regression equation \\
\hline $\begin{array}{l}\text { Benjaponpitak et al. in } \\
1999(17)\end{array}$ & PEFR $(\mathrm{L} / \mathrm{min})=[3.52 \times$ height $(\mathrm{cm})]-186.80$ & PEFR $(\mathrm{L} / \mathrm{min})=[3.48 \times$ height $(\mathrm{cm})]-204.11$ \\
This study & PEFR $(\mathrm{L} / \mathrm{min})=(1.34 \times$ height $)+(1.41 \times$ weight $)+$ & PEFR $(\mathrm{L} / \mathrm{min})=(1.31 \times$ height $)+(0.94 \times$ weight $)+$ \\
& $(16.56 \times$ age $)-137.88$ & $(7.30 \times$ age $)-55.27$ \\
\hline
\end{tabular}

PEFR, peak expiratory flow rate.

which is incomparable to this current study as shown Table 2. This study includes all correlation factors in equation for accurate PEFR. The latest study (17) in Thailand was conducted in capital city where with the nutritional and socioeconomic status, as well as environmental situations differ from suburban or rural communities, which, as result, may have impact on the trajectory of children's lives.

As there are wide variations in PEFR due to race, genetic, geographic, anthropometric, nutritional, socioeconomic, ethnicity, age, gender, regional difference $(3,4,6-11)$. This study would be more appropriate to establish its own regional reference values for the northern region of Thailand.

Several studies suggest that PEFR value ranges from every individual; however, the lowest values are commonly recorded in the morning and peaks in the evening. This study recorded the PEFR of schoolchildren from 10.00-13.00 which provided variable for PEFR. We mainly performed the procedure in the morning to maintain the control factor. We recommend the use of this equation to minimize variation.

\section{Limitations}

This study has employed an asymmetrical age distribution that mostly relies on adolescents due to the fact that younger age children cannot properly use the Wright peak flow meter and also has a large disparity in the number of females than males.

PEFR data was collected from the school children in both the morning and afternoon which is other may provide another variable the PEFR.

Further study is recommended and should involve the clinical testing of an equal or larger number of participants from the north of Thailand and be expanded to include additional variants such as air pollution that has recently increased worldwide and has an effect with PEFR values.

\section{Conclusions}

This research study has provided the normal range of PEFR for Thai children aged from 6 to 18 years in Phitsanulok. The data was obtained using the Wright peak flow meter. 
Height, weight, and age were the significant determiners of the PEFR for each sex in the regression equation.

\section{Acknowledgments}

This study was support by the Faculty of Medicine, Naresuan University, Phitsanulok, Thailand. We would like to thank Miss Kornthip Jeephet, Statistics Technical officer, Research Center, Faculty of Medicine, Naresuan University, for her assistance with the statistical analysis. We are grateful to Mr. Thom Locke, Academic English Program Teacher, Master of Philosophy Degrees from Boston University, and Miss Judely Marish Canete for proving and checking English accuracy.

Funding: None.

\section{Footnote}

Data Sharing Statement: Available at http://dx.doi. org/10.21037/jtd-20-1846

Conflicts of Interest: Both authors have completed the ICMJE uniform disclosure form available at (http://dx.doi. org/10.21037/jtd-20-1846). The authors have no conflicts of interest to declare.

Ethical Statement: The authors are accountable for all aspects of the work in ensuring that questions related to the accuracy or integrity of any part of the work are appropriately investigated and resolved. The study was conducted in accordance with the Declaration of Helsinki (as revised in 2013). The study was approved by Naresuan University Institutional Review Board (No. 155/57). The parents of all study participants gave both verbal and written informed consent before study enrollment.

Open Access Statement: This is an Open Access article distributed in accordance with the Creative Commons Attribution-NonCommercial-NoDerivs 4.0 International License (CC BY-NC-ND 4.0), which permits the noncommercial replication and distribution of the article with the strict proviso that no changes or edits are made and the original work is properly cited (including links to both the formal publication through the relevant DOI and the license). See: https://creativecommons.org/licenses/by-nc-nd/4.0/.

\section{References}

1. Global Initiative for asthma. Global Strategy for asthma management and prevention. Accessed April 21, 2020. Available online: https://ginasthma.org/wp-content/ uploads/2020/04/GINA-2020-full-report_-final-_wms.pdf

2. National Asthma Education and Prevention Program: Expert panel report 3 (EPR3): Guidelines for the diagnosis and management of asthma. Bethesda, MD: National Heart, Lung, and Blood Institute 2007. (NIH publication no. 08-4051). www.nhlbi.nih.gov/guidelines/asthma/ asthgdln.htm (Accessed on April 21, 2020).

3. Gulla KM, Kabra SK. Peak Expiratory Flow Rate as a Monitoring Tool in Asthma. Indian J Pediatr 2017;84:573-4.

4. Dobra R, Equi A. How to use peak expiratory flow rate. Arch Dis Child Educ Pract Ed 2018;103:158-62.

5. Mridha MAA, Amin MR, Kabir ARML. Peak Expiratory Flow Rate (PEFR)-A Simple Ventilatory Lung Function Test. J Shaheed Suhrawardy Med Coll 2011;32:44-7.

6. Gupta S, Mittal S, Kumar A, et al. Peak expiratory flow rate of healthy school children living at high altitude. $\mathrm{N}$ Am J Med Sci 2013;5:422-6.

7. Radziavicius FR, Martins LC, Radziavicius CC, et al. Peak expiratory flow values are higher in older and taller healthy male children: an observational study. Clin Invest Med 2010;33:E92.

8. $\mathrm{Cb} \mathrm{M}, \mathrm{Sc} \mathrm{K}$, Babu M. Peak expiratory flow rate in healthy rural school going children (5-16 years) of bellur region for construction of nomogram. J Clin Diagn Res 2013;7:2844-6.

9. Bakki B, Hammangabdo A, Talle MA, et al. Peak expiratory flow in normal medical students in Maiduguri, Borno state, Nigeria. Pan Afr Med J 2012;12:73.

10. Agaba PA, Thacher TD, Angyo IA, et al. Peak expiratory flow rates in healthy Nigerian children. J Trop Pediatr 2003;49:157-9.

11. Takase M, Sakata H, Shikada M, et al. Development of reference equations for spirometry in Japanese children aged 6-18 years. Pediatr Pulmonol 2013;48:35-44.

12. Ghazal-Musmar S, Musmar M, Minawi WA. Comparison of peak expiratory flow rates applying European and Iranian equations to Palestinian students. East Mediterr Health J 2010;16:386-90.

13. Gharagozlo M, Khajooe V, Moin M, et al. Peak Expiratory Flow Rate in Healthy Children from Tehran. Iran JMed Sci 2003;28:26-8. 
14. Wun YT, Chan MS, Wong NM, et al. A curvilinear nomogram of peak expiratory flow rate for the young. J Asthma 2013;50:39-44.

15. Oneş U, Somer A, Sapan N, et al. Peak expiratory flow rates in healthy Turkish children living in Istanbul, Turkey. Allergy Asthma Proc 2004;25:313-20.

16. Das B, Ghosh T, Gangopadhyay S. Peak expiratory flow rate among child labourers in West Bengal, India. Indian Pediatr 2011;48:487.

17. Benjaponpitak S, Direkwattanachai C, Kraisarin C, et al. Peak expiratory flow rate values of students in Bangkok. J Med Assoc Thai 1999;82 Suppl 1:S137-43.

18. Seo WH, Ahn SH, Park SH, et al. The standard range of peak expiratory flow rates of Korean children. Asian Pac J Allergy Immunol 2011;29:143-9.

19. Gautrin D, D'Aquino LC, Gagnon G, et al. Comparison between peak expiratory flow rates (PEFR) and FEV1 in the monitoring of asthmatic subjects at an outpatient clinic. Chest 1994;106:1419-26.

20. Connolly CK, Chan NS. Relationship between different measurements of respiratory function in asthma. Respiration. 1987;52:22-33.

21. Kelly CA, Gibson GJ. Relation between FEV1 and peak expiratory flow in patients with chronic airflow obstruction. Thorax 1988;43:335-6.

22. Hsu KH, Jenkins DE, Hsi BP, et al. Ventilatory functions of normal children and young adults-Mexican-American, white, and black. II. Wright peak flowmeter. J Pediatr 1979;95:192-6.

23. Dhungel KU, Parthasarathy D, Dipali S. Peak expiratory

Cite this article as: Srisingh K, Phuaksaman C. The reference values of peak expiratory flow rate in Thailand children. J Thorac Dis 2021;13(1):31-38. doi: 10.21037/jtd-20-1846 flow rate of Nepalese children and young adults. Kathmandu Univ Med J (KUMJ) 2008;6:346-54.

24. Lu Y, Zheng J, Liu C, Ai T, et al. Peak expiratory flow among healthy children aged 5-14 years in China. J Thorac Dis 2018;10:1377-85.

25. Swaminathan S, Diffey B, Vaz M. Evaluating the suitability of prediction equations for lung function in Indian children: a practical approach. Indian Pediatr 2006;43:680-98.

26. Pulickal AS, Fernandez GV. Peak expiratory flow rate in healthy rural south Indian school children predicted from body height. Indian J Public Health 2007;51:117-9.

27. Cb M, Sc K, Babu M. Peak Expiratory Flow Rate In Healthy Rural School Going Children (5-16 Years) of Bellur Region For Construction of Nomogram. J Clin Diagn Res 2013;7:2844-6.

28. Vijay Krishna K, Arun Kumar S, Shivaprasad V, et al. Peak Expiratory flow rate and its Correlation with age in normal School Children. Int. Res. J. Medical Sci 2014;2:1-3.

29. Sadiq S, Rizvi NA, Soleja FK, et al. Factors affecting spirometry reference range in growing children. Pak J Med Sci 2019;35:1587-91.

30. Raju PS, Prasad KV, Ramana YV, et al. Study on Lung Function Tests and Prediction Equations in Indian Male Children. Indian Pediatr 2003;40:705-11.

31. Sharma M, Sharma RB, Choudhary R. Peak expiratory flow rates in children of western Rajasthan 7-14 years of age. Pak J Physiol 2012;8:45-8.

32. Carson JW, Hoey H, Taylor MR. Growth and other factors affecting peak expiratory flow rate. Arch Dis Child 1989;64:96-102. 